\title{
İmalat Tesislerinde Yangın Tesisatlarından Kaynaklanan Risklerin Sıralama Yöntemi ile Analizi
}

\author{
Analysis of the Risk Arising from Fire Installations in \\ Manufacturing Facilities By Ranking Method
}

Ahmetcan ALKOÇ, Fatih YILMAZ

\begin{abstract}
ÖZET
Yangın ölüm, yaralanma ve büyük maddi kayıplara neden olan bir afettir. İmalat tesislerindeki eski veya mevcut yangın tesisatları için, standartlara dayanan detaylı ancak geleneksel kontrol listesi şeklindeki yangın risk analizleri gerçekçi olmayan sonuçlar doğurabilir. Bu sebeple, yeni ve daha bütüncül yaklaşımların da uygulanması gerekmektedir. Bu makale, Türkiye'de imalat tesisleri için "Yangın Güvenliği Risk Sıralama Sistemi" șeklinde bir risk analiz yöntemi önermeyi amaçlamaktadır. Bu amaçla, 30 imalat tesisinde uygulama yapılmış ve yangın güvenlik sıralaması skor tablosu oluşturulmuștur. Sonuçlara göre, uygulama yapılan işletmelerin yüzde 93 'ünün yangın tesisatlarında uygunsuzluk tespit edilmiş, \% 67'sinin orta ya da yüksek düzeyde yangın riski taşıdığı anlaşılmıştır.
\end{abstract}

Anahtar Kelimeler: Bulanık AHP, Sıralama Yöntemi, Risk Değerlendirme, Yangın Risk Analizi, Yangın Tesisatı

\section{ABSTRACT}

Fire is a disaster that causes death, injury and major financial loss. For old or existing fire installations in manufacturing facilities, detailed but traditional check-list fire risk analyzes based on standards can produce unrealistic results. For this reason, new and more holistic approaches need to be implemented. This article is for manufacturing facilities in Turkey, "Fire Safety Risk Ranking System" in the form of a risk analysis method aims to propose. For this purpose, application was made in 30 manufacturing facilities and a fire safety ranking score table was created. According to the results, 93 percent of the applications were found to be nonconformities in fire installations, it was understood that $67 \%$ had a medium or high risk of fire.

Keywords: Fuzzy AHP, Ranking Method, Risk Analysis, Risk Assessment, Fire System

Ahmetcan ALKOÇ - Yıldız Teknik Üniversitesi, Makine Fakültesi, Konstrüksiyon Anabilim Dalı İstanbul, Türkiye

Ahmetcan ALKOC - Yildiz Technical University, Faculty of Mechanical Engineering, Department of Construction, Istanbul, Turkey

acanalkoc@gmail.com

Doç. Dr. Fatih YILMAZ - Yıldız Teknik Üniversitesi, Makine Fakültesi, Endüstri Mühendisliği Bölümü İstanbul, Türkiye

Assoc. Prof. Fatih YILMAZ - Yildiz Technical University, Faculty of Mechanical Engineering, Department of Indutrial Engineering, Istanbul, Turkey

ftyilmaz@yildiz.edu.tr

Received/Geliş Tarihi : 15.04.2018 Accepted/Kabul Tarihi: 07.06.2018 


\section{GİRIŞ}

Türkiye'de 2017 yılında fabrika yangınlarının sayısı 2016 yılına göre \% 7,8 artış göstermiş, 2014 yılına göre artış oranı \% 25,9'u bulmuştur. 2017 yılında toplam 166 fabrikaya yangın nedeniyle müdahale edilmiştir [1]. Gelişen teknoloji ve yasal zorunluluklar ile birlikte, fabrikalarda hem çalışanlar hem de çevrede yaşayan halk için daha güvenli bir çalışma ortamı yaratmak amacıyla yangın risklerinin belirlenmesi, yangın güvenlik sistemlerinin oluşturulması ve denetlenmesinin önemi artmıştır. 6331 sayılı İş Sağlığı ve Güvenliği Kanununun [2] ilgili maddeleri uyarınca işverenlere, işyerlerinde var olan ya da dışarıdan gelebilecek tehlikelerin belirlenmesi ve bertaraf edilmesi için risk değerlendirmesi yapma zorunluluğu getirilmiştir. Risk değerlendirmesinin yapılması kadar güncel tutulması da, iş yerinde sürekli iyileştirmenin sağlanması açısından önemli$\operatorname{dir}[3]$.

Yangın tesisatlarının periyodik kontrollerinin, İş Ekipmanlarının Kullanımında Sağlık ve Güvenlik Şartları Yönetmeliğinde [4] düzenlendiği gibi yılda en az bir defa yapılması zorunludur. Binaların Yangından Korunması Hakkındaki Yönetmelik [5] de, her türlü yapı ve tesisin tasarım, yapım, işletim, bakım ve kullanım aşamalarında oluşabilecek yangınların minimuma indirilmesi, can ve mal kaybının en aza indirilerek söndürülmesinin sağlanması, yangın öncesinde ve sırasında alınacak tedbirlerin, organizasyonun, eğitimin ve denetimin usul ve esaslarının belirlenmesi amacıyla yayınlanmıştır.

Teknolojik gelişmeler ile birlikte imalat tesislerinde kullanılan kıymetli ve hassas makineler, çok katlı ve çok amaçlı inşa edilen binalar ve depolarda tutulan değerli malzemeler çeşitli riskleri de beraberinde getirmiştir. Yeni riskler ortaya çıkarken güvenlik önlemleri de değişime uğramıştır. Bu risklerden, neden olduğu can ve mal kayıpları gibi yıkıcı sonuçları itibarıyla en önemlilerinden biri de yangındır. Yangın risklerini bertaraf etmeye yönelik yeni güvenlik önlemleri de geliştirilmektedir. Önceden haber alan, algılayan, uyaran ve uygun çözüm bulan yeni cihazlar ve sistemlerin sayısı artmaktadır. Yangınlara karşı korunma, söndürme ve güvenlik sistemleri, yangınların işletmelerde neden olabileceği potansiyel zararlar göz önüne alınarak her geçen gün önem kazanmaktadır [6].

İşletmelerde veya AVM, hastane, okul gibi toplu yaşam alanlarında yangına karşı en uygun güvenlik tedbirlerini belirlemek için, yangın risklerinin gerçekçi şekilde belirlenmesi ve uygun yöntemlerin geliştirilmesi gerekmektedir. Yangın riskleri de çeşitli risk değerlendirme teknikleriyle ele alınmaktadır [7]. Yangın risk analizi; risk yaratacak ölçütlerin belirlenmesi, önem düzeyinin belirlenmesi, hesaplanması ile riski azaltmak için üstlenilmesi gereken önleme ve koruma önlemlerinin belirlenmesini amaçlamaktadır [8].

Tasarlanmış her bir yapı risk analizi bakış açısıyla incelendiğinde, yangın olasılığının sıfırlanamayacağı kabul edilir. Bu nedenle kusursuz bir yangın güvenliği sağlanması mümkün değildir. Bununla birlikte, yangından korunma ve yapıların yangın güvenliği ile ilgili sorunları bir bütün olarak ve sistematik şekilde incelemek riskin azaltılması açısından önem taşımaktadır. Bir plan doğrultusunda ilk önce ölçütleri ve bu ölçütlerin önem derecelerini saptamak, daha sonra bu ölçütlere cevap verebilecek ve saptanan hedeflere götürecek bir strateji oluşturmak ve formüle etmek gerekmektedir [9].

Yangın ölüm, yaralanma ve büyük maddi kayıplara neden olan bir afettir. Yangın riskleri çok çeşitli olup bu risklerin bir kısmı yangın tesisatlarından kaynaklanmaktadır. İmalat tesislerindeki eski yangın tesisatları için, standartlara dayanan detaylı ancak geleneksel 'kontrol listesi" 
şeklindeki yangın risk analizleri gerçekçi olmayan sonuçlar ortaya çıkarabilir. Bu sebeple, yeni ve daha bütüncül yaklaşımların da uygulanması gerekmektedir.

$\mathrm{Bu}$ makale, Türkiye'de imalat tesisleri için "Yangın Güvenliği Risk Sıralama Sistemi” şeklinde bir risk analiz yöntemi önermeyi amaçlamaktadır. Bu amaçla, 2007 yılında yürürlüğe giren Binaların Yangından Korunması Hakkındaki Yönetmeliğe [5] göre toplam kapalı kullanım alanı $1000 \mathrm{~m}^{2}$ den büyük 30 imalathanede uygulama yapılmıştır. Risk skoru hesaplamada kullanılan yangın güvenlik kriterleri, ulusal ve uluslararası mevzuat ve standartlar dikkate alınarak oluşturulmuştur. Bu kriterler; bina özellikleri, yangın güvenlik sistemleri ve yönetim sistemleri olmak üzere üç ana bölüme ayrılmıştır. Öncelikle, Analitik Hiyerarşi Süreci (AHP) yöntemi ile bu kriterlere ilişkin ağırlıklar belirlenmiştir. Bu amaçla yangın uzmanlarına bir anket uygulanmıştır. Hesaplanan ağırlıklar sıralama yöntemiyle yeniden hesaplanarak, imalat işletmeleri için yangın risk skor ve sıralama tabloları oluşturulmuştur.

\section{ARAŞTIRMA YÖNTEMİ}

\section{A. Bulanık AHP}

Çok kriterli karar verme, istenen amaca ulaşmak için nitel ve nicel kriterler kullanarak mevcut alternatiflerin değerlendirilerek en uygun alternatifin seçilmesi veya alternatiflerin sıralanması şeklinde tanımlanabilir. Çok kriterli karar verme süreci, uygun alternatifler arasından en iyi seçeneğin bulunmasına yönelik bir süreçtir. Çok kriterli karar verme ise, alternatiflerin birden fazla kriter bakımından sıralanmasında kullanılmaktadır ve çok geniş kullanım alanına sahiptir. Çok kriterli karar verme problemlerinin çözümü için geliştirilen yöntemler, karar verme sürecinde çok sayıda ve genellikle birbirleriyle çelişen kriterlerin bulunduğu durumlarda kullanılmaktadır [10-13].
Çok kriterli karar verme yöntemleri, çalışan sağlığı ve güvenliği ile ilgili araştırmalarda sıkça başvurulan yöntemdir. Örneğin; sıcak ve nemli ortamlarda çalışanların iş güvenliği koşullarının incelenmesinde [14], yol inşaatlarında iş güvenliği faktörleri ve performansının ölçülmesinde [15], işyerlerinde davranışsal tabanlı iş güvenliği yönetiminde hatalı davranışsal risklerin belirlenmesinde [16], imalat sanayiinde iş güvenliği risklerinin belirlenmesinde [17], inşaat kazı çalışmalarında iş güvenliği risklerinin belirlenmesinde [18] çok kriterli karar verme yöntemleri kullanılmıştır. İş güvenliği, çalışan sağlığı, verimlilik ve performans ölçümü ile ilgili konularda bu metod yaygın olarak kullanılmaktadır [19-23].

Thomas L. Saaty [24] tarafından 1970'li yıllarda özel bir programlama problemini çözmek üzere Çok Kriterli Karar Verme tekniklerinden olan Analitik Hiyerarşi Yöntemi (AHP) ortaya atılmışıtır. Hiyerarşide alt başlıklara ayırma işlemi ağaca benzer bir yapıyla gösterilir. Hiyerarşide kullanılan bu ağaç yapısı problemi basitleştirmeye yardımcı olur. AHP ile oluşturulan hiyerarşik yapıda, hiyerarşinin en üst kısmında en iyi kararı verme ya da en iyi alternatifi seçme amacı bulunmaktadır. Alt seviyelere inildikçe, amaca katkıda bulunan özellikler görülür. Bu özellikler hiyerarşide daha alt seviyelere inilirse ayrıntılandırılabilir. En alt seviyede ise karar seçenekleri bulunur [25]. AHP, alternatiflerin ortak bir kritere göre ikili karşılaştırılmasına dayanan bir ölçüm teorisidir. AHP çok kriterli ve çok seçenekli problemlerin sonuca ulaşmasında karar vericilere önemli yardımlar sağlamaktadır. AHP problemleri birden fazla seviyeden meydana gelen bir hiyerarşik yapı ile oluşturulmaktadır. Analitik Hiyerarşi Sürecinde her sorun için amaç, kriter, olası alt kriter seviyeleri ve alternatiflerden oluşan bir hiyerarşik yapı kullanılır [26].

$\mathrm{Bu}$ çalışsmada risk analiz yöntemi olarak Çok Kriterli Karar Verme tekniklerinden olan "Analitik Hiyerarşi Pro- 
sesi” (AHP) tekniği ile Sıralama yöntemleri birlikte kullanılmıştır. AHP, hem öznel hem de nesnel değerlendirme ölçütlerini dikkate alabilen ve yaygın olarak kullanılan bir "Çok Kriterli Karar Verme Tekniği”dir. Anlaşılmasının kolay olması ve basit matematik hesaplamaları içermesi sebebiyle, AHP oldukça büyük bir ilgi görmüş ve birçok alanda kullanılmıştır [27].

AHP süreci Zhao [28] tarafından beş adımda şu şekilde tanımlanmıştır:

1. Adım: Sorunu karar öğeleri (nitelikler) hiyerarşisine dönüştürerek bir karar hiyerarşisi oluşturmak,

2. Adım: Karar unsurlarının eşli karşılaştırması ile girdi toplamak,

3. Adım: Giriş verisinin bir "Tutarlılık Testi"ni yerine getirip getirmediğini belirlemek,

4. Adım: Karar unsurlarının göreceli ağırlıklarını hesaplamak,

5. Adım: Her bir karar unsurunun ağırlıklı puanlarını toplamak ve karar alternatiflerini sıralamak.

AHP, yangın güvenlik ölçütlerinin çoğu zaman hatalı tanımlanmasından dolayı, yangın risk kriterlerinin ve önem düzeylerinin belirlenmesinde uygun yöntemlerden biri olarak görülmektedir [29]. AHP, mevcut binalar için yangın risk sıralama yaklaşımı olarak Zhao \& diğ. [28] tarafından da bir çalışmada uygulanmış, yangın güvenlik ölçütlerinin tanımlanması ve karşılaştırmasını kolaylaştırmak amacıyla başka çalışmalarda da kullanılmıştır [30].

\section{B. Sıralama Yöntemi}

Bilimsel yazında bu yöntem; yangın güvenliği sıralama sistemi, yangın risk sıralama sistemi veya yangın güvenliği değerlendirme sistemi olarak bilinmektedir [29-32]. Çok kriterli karar verme tekniğinden yararlanılarak yangın güvenlik kriterlerinin sıralamasının yapıldığı süreçtir [30, 3335]. Bir yangın güvenliği sıralama sisteminin amacı, mevcut binaların çeşitli yangın güvenlik kriterlerinin perfor-

mansını değerlendirmek ve yangın riski seviyesini ölçmektir. Muhtelif binalar için elde edilen yangın riski seviyeleri, yangın güvenlik performansında iyileştirme için alınacak aksiyonların önceliklendirilmesi için temel oluşturmaktadır [32].

Birçok ülkede yangın güvenliği risk sıralama yöntemleri, binaların yangın güvenlik düzeyinin değerlendirilmesine yardımcı olmak için geliştirilmiş ve uygulanmıştır. Örneğin, ABD'de yangın risk sıralamasına göre bir Yangın Güvenliği Değerlendirme Sistemi geliştirilmiştir [36]. Bu sistem, belirli işyerleri için NFPA 101 Yaşam Güvenliği Standardına (1994) eşdeğerlikleri belirlemek için çok özellikli bir yaklaşım sunmaktadır [37]. Chow \& Lui [38] Hong Kong'daki eğlence mekânları için bir yangın güvenliği sıralama sistemi önermiştir. Yine Hong Kong'da, Chow [35] yüksek katlı konut dışı binalar için bir sıralama tekniği geliştirmiştir.

Sıralama yönteminin araştırmamıza benzeyen bir başka uygulaması Suudi Arabistan'da öğrenci barınma tesislerinin yangın güvenliği performansını belirlemek için kullanılmıştır [30]. Yangın risk sıralama sistemleri, kullanım kolaylı̆̆ı, maliyet etkinliği ve göreceli yangın riskinin hızlı ve basit bir tahminini yapma gibi birçok avantaj sunmaktadır. Yapılan yazın taramasında, imalat tesisleri için, yangın tesisatlarından kaynaklanan risklerin analizinde sıralama yönteminin kullanıldığı bir başka çalışmaya rastlanmamıştır.

Sıralama yöntemi; bakım yönetimi, bina güvenlik sistemlerinin iyileştirilmesi, malzemelerin önceliklendirilmesi ve uygun şekilde tahsis edilmesi gibi konumuza uygun benzer başka alanlarda da kullanılmış bir yöntemdir [30, 39]. Bununla birlikte, yangın güvenliği sıralama sistemlerinin kullanımında dezavantajlar da vardır. Diğer yöntemlere göre tekdüze bir sistem değildir. Bu nedenle, farklı kullanım tipli yapılar için farklı yöntemlerin geliştirilmesi gerek- 
tiği de ifade edilmektedir [40].

Sıralama yönteminin dayandığı temel varsayım, yangın risk faktörlerini oluşturan kriterlerin birbirlerine karşı göreceli önem düzeylerinin bulunmasıdır. Farklı işletmelerde, farklı yangın risk kriterleri bulunmaktadır. Bununla birlikte, bu kriterlerin önem derecesi işletmelerde toplam yangın risk skorunu arttırabilmekte veya azaltabilmektedir. Ayrıca, kontrol listesi ile "0-1" ya da "var-yok" şeklinde yapılan tekdüze risk analizleri yeterli sayısal verileri içermemekte, bu durum yangın risklerinin değerlendirilmesini zorlaştırmakta ve isabet oranını düşürmektedir.

Bu çalışmadaki yöntemin amacı; her bir risk kriterinin önem derecesinin, yangın uzmanlarının görüşleri doğrultusunda çok kriterli karar verme yöntemi olan Analitik Hiyerarşi Süreci ile hesaplanarak, hesaplanan risk puanlarının işletmelerde yapılan risk analiz uygulamasına yansıtılması ve işletmeler için toplam yangın risk skorunun hesaplanmasıdır. Bu yöntemle yangın riskleri nicel yöntemle hesaplanmakta, risk değerlendirmesinin hassasiyet düzeyi artmaktadır. Böylece, işletmede alınması gereken tedbirlerin ve önceliklerin belirlenmesinde, önleyici çalışmaların planlanmasında, iş sağlığı ve güvenliği ve yangın uzmanlarına destek olabilecek nicel bilgiler üretilmektedir.

Yangın risk sıralama yöntemiyle hazırlanan bu çalışma üç aşamalı olarak gerçekleştirilmiştir. İlk aşamada imalat tesislerinde yangın tesisatlarıyla ilgili her bir risk faktörü yürürlükteki mevzuat ve standartlar doğrultusunda belirlenmiştir. Daha sonra bu faktörleri oluşturan, Tablo 2 ve 3 'te belirtilen kriter ve alt kriterlerin önem derecesi yangın uzmanlarına uygulanan bir anketle belirlenmiş, elde edilen sonuçlar AHP yöntemi ile hesaplanarak her bir yangın güvenlik kriterinin ve alt kriterinin ağırlıklı risk puanları belirlenmiştir. İkinci aşamada ise; AHP ile hesaplanan ağırlıklı risk puanları, uygulama kapsamındaki işletmelerde kontrol listesi yöntemiyle yapılan risk analiz uygulamasından elde edilen risk puanları ile çarpılarak, her bir tesis için toplam risk puanları belirlenmiştir. Son aşamada ise, toplam risk puanlarından elde edilen verilerle, tesislerdeki yangın risk sıralama puan çizelgesi oluşturulmuştur.

\section{UYGULAMA}

\section{A. Veri Toplama Yöntemi}

Araştırma kapsamında bir yangın risk sıralama sistemini geliştirmek amacıyla, bilimsel yazın taraması ve mevcut standartlara göre belirlenen yangın güvenlik kriter ve alt kriterlerin ağırlıklarını hesaplamak için, AHP yöntemine uygun bir anket hazırlanmıştır. Anket, Tablo 1'de gösterildiği gibi, eşleştirilmiş karşılaştırma tablolarında tanımlanmış yangın güvenlik kriterlerini ve niteliklerini yapılandırarak basitleştirilmiş bir şekilde sunmuştur.

Yanıtlar, yangın konusunda 20 yıldan fazla tecrübeli uzmanlardan kişisel mülakatlar yoluyla ve her değerlendirmeci için ayrı ayrı formlar halinde toplanmıştır. Anket toplam 5 uzmana uygulanmıştır. Anketin niteliği, amacı ve sonucu katılımcılara ayrıntılı bir şekilde açıklanmıştır. Katılımcilardan anket formunda her bir satırda verilen yangın risk kriterinin, satır sonunda belirtilen diğer risk kriterine göre önem derecesini belirlemesi istenmiştir. Örneğin; kriterlerden her ikisi de eşit önemli ise " 1 eşit önemli kutucuğunu”, eğer sağ sütundaki kriter çok önemli ise sağ taraftaki "7 çok önemli" kutucuğunu, sol sütundaki kriter biraz daha önemli ise "sol tarafa yakın olan "3 biraz önemli" kutucuğu işaretlemesi istenmiştir. AHP yöntemi, kriter ağırlıklarını matris yoluyla anketteki puanlara göre hesaplamak için kullanılmıştır. Hesaplanan değerler Tablo 3'te verilmiştir.

Anket; "bina özellikleri”, “yangın güvenlik sistemleri” 
Tablo 1: Çift yönlü karşılaştırma ölçeği

\begin{tabular}{|c|c|c|c|c|c|c|c|c|c|c|}
\hline $\mathrm{X}$ & 9 & 7 & 5 & 3 & 1 & 3 & 5 & 7 & 9 & $\mathrm{Y}$ \\
\hline & $\begin{array}{c}\text { Mutlak } \\
\text { Önemli }\end{array}$ & $\begin{array}{c}\text { Çok } \\
\text { Önemli }\end{array}$ & Önemli & $\begin{array}{c}\text { Biraz } \\
\text { Önemli }\end{array}$ & Önemli & $\begin{array}{c}\text { Biraz } \\
\text { Önemli }\end{array}$ & Önemli & $\begin{array}{c}\text { Çok } \\
\text { Önemli }\end{array}$ & $\begin{array}{c}\text { Mutlak } \\
\text { Önemli }\end{array}$ & \\
\hline
\end{tabular}

ve "yönetim sistemleri" olarak belirlenen risk faktörleri ile bunlara ait kriter ve alt kriterlerin ağırlıklı puanlarının detaylı hesaplanması için oluşturulan karşılaştırmalı başlıklar halinde sunulmuştur;

Tablo 2'de, her bir yangın güvenlik faktörünün toplam göreceli ağırlığının hesaplanması için altı yangın güvenlik kriteri (binanın yapısal durumu, pompa sistemi, yangın dolabı ve tüpleri, acil çıkışlar, yangın algılama ve duman kontrol sistemleri, yangın söndürme sistemleri, yangınla mücadele ve yangın önlemleri) uzmanlar tarafından karşılaştırılmış ve sonuçları verilmiştir.

Tablo 3'te "bina yapısal durumu kriterini" temsil eden alt kriterler uzmanlar tarafından karşılaştırılmış ve sonuçlar verilmiştir.

Tablo 3'te "yönetim sistemleri kriterini" temsil eden yangınla mücadele ve yangın önlemleri alt kriterleri uzmanlar tarafından karşılaştırılmış ve sonuçlar verilmiştir.

Tablo 2: Yangın güvenlik faktörlerinin toplam göreceli önem değerleri

\begin{tabular}{|c|c|c|}
\hline $\begin{array}{l}\text { Yangın Güvenlik } \\
\text { Faktörü }\end{array}$ & $\begin{array}{l}\text { Hesaplanan Göreceli } \\
\text { Ağırlıklandırmalar } \\
\text { (A) }\end{array}$ & $\begin{array}{l}\text { Yangın Güvenlik } \\
\text { Kriteri }\end{array}$ \\
\hline Bina özellikleri & 0,4217 & $\begin{array}{l}\text { Binanın yapısal duru- } \\
\text { mu }\end{array}$ \\
\hline \multirow{4}{*}{$\begin{array}{l}\text { Yangın güvenlik } \\
\text { sistemleri }\end{array}$} & \multirow[t]{4}{*}{0,4762} & Pompa sistemi \\
\hline & & $\begin{array}{l}\text { Yangın dolabı ve } \\
\text { tüpleri }\end{array}$ \\
\hline & & $\begin{array}{l}\text { Acil çıkışlar, yangın } \\
\text { algılama ve duman } \\
\text { kontrol sistemleri }\end{array}$ \\
\hline & & $\begin{array}{l}\text { Yangın söndürme } \\
\text { sistemleri }\end{array}$ \\
\hline Yönetim sistemleri & 0,1021 & $\begin{array}{l}\text { Yangınla mücadele } \\
\text { ve yangın önlemleri }\end{array}$ \\
\hline
\end{tabular}

Tablo 3'te "yangın güvenlik sistemleri kriterini” temsil eden pompa sistemi, yangın dolabı ve tüpleri, acil çıkışlar, yangın söndürme sistemi, yangın algılama ve duman kontrol sistemleri alt kriterleri ayrı ayrı başılıklar şeklinde uzmanlar tarafından birbirleriyle karşılaştırılmış ve sonuçlar verilmiştir. Ayrıca Şekil 1'de ağırlıklandırılmış göreceli yangın güvenlik kriterlerinin yüzdesel olarak risk sıralaması sunulmuştur.

Şekil 1: Ağırlıklandırılmış göreceli yangın güvenlik kriterlerinin yüzdesel olarak risk sıralaması

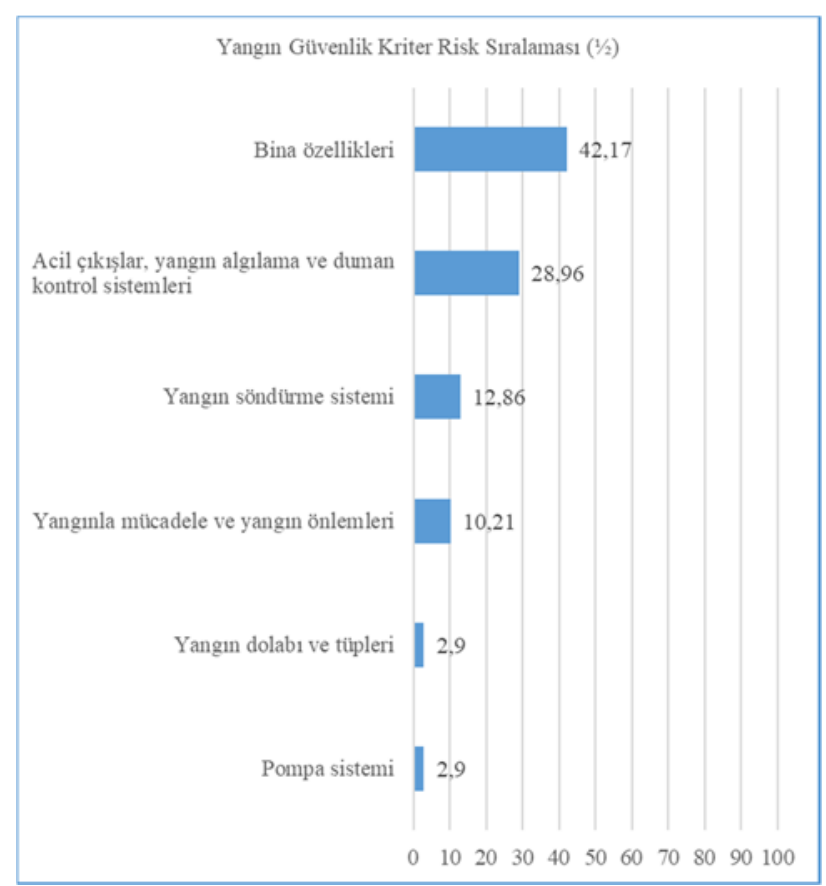

\section{B. Sıralama Yöntemi ile Yangın Risk Analizi Uygulaması}

Uygulama, ilgili mevzuata göre yangın tesisatlarında sulu söndürme sistemi bulundurması zorunlu olan, toplam kapalı kullanım alanı $1000 \mathrm{~m}^{2}$ den büyük, İstanbul ve çevresinde bulunan ve uygulama izni alınabilen 30 imalat tesisinde yapılmıştır. Kriterlerin belirlenmesinde, 2013 
Karaelmas İ̧ Să̆lı̆̆ı ve Güvenliği Dergisi, Cilt 2, Sayı 1, 2018, ss. 1-11

Karaelmas Journal of Occupational Health and Safety, Vol. 2, No. 1, 2018, pp. 1-11

Tablo 3: Yangın güvenlik alt kriterlerinin hesaplanan göreceli önem değerleri

\begin{tabular}{|c|c|c|}
\hline Yangın Güvenlik Kriteri & Hesaplanan Göreceli Ağırlıklandırmalar (a) & Yangın Güvenlik Alt Kriteri \\
\hline \multirow{5}{*}{ Bina yapısal durumu } & 0,08092423 & Bina yangın tesisatına ait projesi \\
\hline & 0,18289129 & $\begin{array}{l}\text { Bina tesisat projesinde belirtilen tesisat } \\
\text { ölçüleri ile uygulamadaki farklııklar }\end{array}$ \\
\hline & 0,050604 & $\begin{array}{l}\text { Binanın yapısal durumunda kullanılan } \\
\text { malzemeler }\end{array}$ \\
\hline & 0,03622403 & $\begin{array}{l}\text { Elektrik tesisatında ana panoda } 300 \mathrm{~mA} \\
\text { yangın rölesi }\end{array}$ \\
\hline & 0,07105645 & Elektrik iç tesisat ve topraklama ölçümleri \\
\hline \multirow{5}{*}{ Yangınla mücadele ve yangın önlemleri } & 0,02492261 & Acil durum eylem planı \\
\hline & 0,02492261 & Yangın tatbikat eğitimleri \\
\hline & 0,01401833 & Yangın ekiplerine ait talimatlar \\
\hline & 0,01991971 & Yangın panosu \\
\hline & 0,01831674 & Yangın tesisatı periyodik kontrol raporu \\
\hline \multirow{5}{*}{ Pompa sistemi } & 0,006351 & Pompa istasyonu \\
\hline & 0,0042978 & $\begin{array}{l}\text { Yedek dizel motor tahrikli veya elektrikli } \\
\text { pompa (jeneratör destekli) }\end{array}$ \\
\hline & 0,0050808 & Yangın pompaları sıralı düzenli çalışması \\
\hline & 0,0085144 & $\begin{array}{l}\text { Pompaların tüm bileşenlerinin çalışıp } \\
\text { çalışmaması }\end{array}$ \\
\hline & 0,004756 & Jokey pompa \\
\hline \multirow{5}{*}{ Yangın dolabı ve tüpleri } & 0,0058 & Yangın tüpleri \\
\hline & 0,0058 & Yangın dolabı \\
\hline & 0,0058 & Yangın hortumu \\
\hline & 0,0058 & Yangın vanaları \\
\hline & 0,0058 & $\begin{array}{l}\text { Yangın dolap ve tüpü uyarı levhaları, bakım } \\
\text { kayıtları ve talimatları }\end{array}$ \\
\hline \multirow{5}{*}{$\begin{array}{l}\text { Acil çıkışlar, yangın algılama ve duman kont- } \\
\text { rol sistemleri }\end{array}$} & 0,04984016 & $\begin{array}{l}\text { Yapılarda kaçış merdivenlerinin, kapılarının } \\
\text { yangına dayanıklıı̆ı̆ }\end{array}$ \\
\hline & 0,05548736 & Kaçış yollarının boyutları \\
\hline & 0,06721616 & $\begin{array}{l}\text { Duman alev dedektörleri ve bağı olduğu sesli } \\
\text { ikaz sistemleri }\end{array}$ \\
\hline & 0,06721616 & Alarm sistemleri ve enerji kaynakları \\
\hline & 0,04984016 & Acil çıkış işaretleri ve çizgileri \\
\hline \multirow{5}{*}{ Yangın söndürme sistemi } & 0,02572 & $\begin{array}{l}\text { Şebeke, yangın suyu, hidrant hatları ve depo } \\
\text { bağlantiları }\end{array}$ \\
\hline & 0,02572 & Yangın pompaları debi ve basınçları \\
\hline & 0,02572 & Ham su depoları ve yeterlilikleri \\
\hline & 0,02572 & Sprinkler sistemi proje uygunluğu \\
\hline & 0,02572 & Yangın tesisat dayanım testi \\
\hline
\end{tabular}


yılında yürürlüğe giren İş Ekipmanlarının Kullanımında Sağlık ve Güvenlik Şartları Yönetmeliğinde [4] belirtilen standartlar ile 2007 yılında yürürlüğe giren Binaların Yangından Korunması Hakkındaki Yönetmeliğe [5] uygun olarak düzenlenmiş Tablo 3'te bulunan yangın güvenlik kriterleri ve alt kriterleri dikkate alınmıştır. Kriter ve alt kriterlerin değerlendirilmesi ilgili mevzuatın gerekliliklerine göre yapılmıştır. İmalat tesislerindeki inceleme ve kontroller, işletmelerin iş güvenliği uzmanları ile beraber yürütülerek, tespitlerin Tablo 3 'te sunulan kriterlere uygun ve olabildiğince doğru şekilde yapılması amaçlanmıştır. Değerlendirme ölçeği Tablo 4'e göre yapılmıştır. Şekil 2'de adım adım analiz süreci verilmiştir.

Tablo 4: Değerlendirme ölçeğinin sınıflandırılması

\begin{tabular}{|l|c|}
\hline \multicolumn{1}{|c|}{ Değerlendirme kategorisi } & Skor (s) \\
\hline Uygunsuz & 0 \\
\hline Uygun & 1 \\
\hline
\end{tabular}

Şekil 2: İmalat tesisleri yangın güvenliği risk sıralama sistemi için adım adım analiz süreci

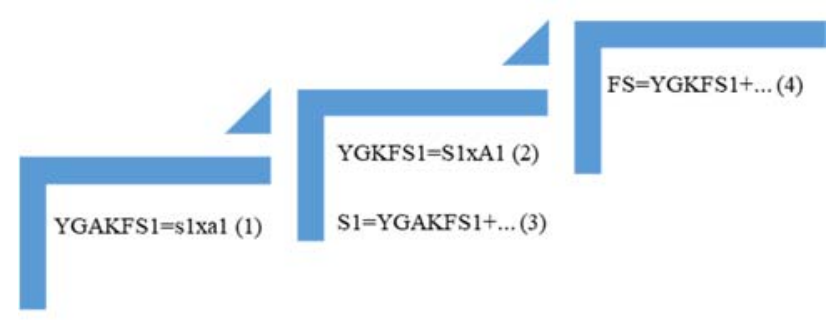

FS $\quad=$ Final Skor

YGKFS = Yangın Güvenlik Kriter Final Skoru

S1 = Yangin Güvenlik Kriter Skoru

A1 = Yangın Güvenlik Kriter Ağırlı̆ğ

YGAKFS = Yangın Güvenlik Alt Kriteri Final Skoru

s1 = Yangın Güvenlik Alt Kriteri Skoru

a1 = Yangın Güvenlik Alt Kriteri Ağırlığı

- Tablo 3'te bulunan her bir yangın güvenlik kriteri, Tablo 4'deki verilere dayanarak skorlara dönüştürülmüştür.

- Bu skorlar, Tablo 3'te sunulan AHP yöntemiyle hesaplanan ağırlıklandırılmış puanlarıyla çarpılarak her bir kriter için ağıllıklı risk skoru hesaplanmıştır.

- Her bir risk faktörünün (bina özellikleri, yangın güvenlik sistemleri ve yönetim sistemleri) final skorunu elde etmek için, her bir kriter altındaki aşama 2'de türetilen tüm alt kriterlerin sonuç skorları toplanmış ve Tablo 2'deki kriterler için hesaplanan ağırlıklı puanlar ile çarpılmıştır.

- Kriterlerin final skorları toplamı tesisin nihai toplam puanını oluşturmuştur.

- Genel puanların karşılaşıııılması sonucu, uygulama yapılan tesislerin Yangın Güvenlik Sıralaması yapılmıştır.

\section{Bulgular}

Sıralama yöntemi ile yapılan risk analiz uygulamasından elde edilen sonuçlar Tablo 5'te sunulmuştur. Elde edilen skorlara göre oluşan tesis sıralaması ise Şekil 3'te verilmiştir.

Şekil 3: İmalat tesislerinin toplam risk skorları ve firma sıralamaları

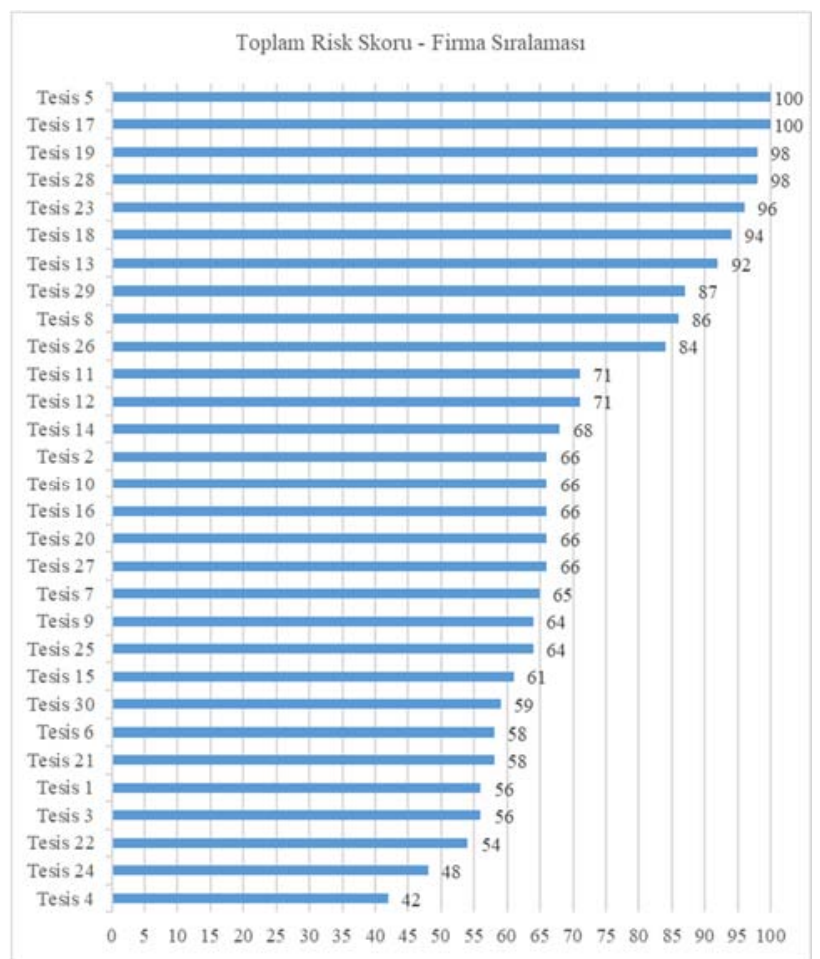

Uygulama yapılan 30 tesiste, yangın risk sıralama yöntemine göre 100 tam puan alan sadece 2 tesis bulunuyorken, 70 puanın altında kalan 18 tesis tespit edilmiştir. Bunlardan 2 tanesi 50 puanın altında çok düşük skorda kalırken, toplam 8 tesisin puanı 60'ın altındadır. 
Tablo 5: Uygulama yapılan imalat tesislerinde kontrol puanlarının, ağırlıklı risk puanları ile çarpımı sonucu (SxA) elde edilen toplam risk skorları tablosu

\begin{tabular}{|c|c|c|c|c|c|c|c|c|c|c|}
\hline \multirow[t]{2}{*}{ Yangın Güvenlik Risk Faktörleri } & \multicolumn{10}{|c|}{ Firmaların Yangın Risk Final Skorları (\%) } \\
\hline & F1 & F2 & F3 & F4 & F5 & F6 & F7 & F8 & F9 & F10 \\
\hline Bina özellikleri & 15,8 & 15,8 & 15,8 & 15,8 & 42,2 & 12,2 & 15,8 & 31,4 & 15,8 & 15,8 \\
\hline Yangın güvenlik sistemleri & 31,8 & 40,2 & 31,8 & 23,7 & 47,6 & 37,4 & 46,7 & 44,6 & 38,2 & 41,8 \\
\hline Yönetim sistemleri & 8,4 & 10 & 8,4 & 2,5 & 10 & 8,4 & 2,5 & 10 & 10 & 8,4 \\
\hline Toplam Skor & 56 & 66 & 56 & 42 & 100 & 58 & 65 & 86 & 64 & 66 \\
\hline Yangın Güvenlik Risk Faktörleri & F11 & $\mathrm{F} 12$ & F13 & F14 & F15 & F16 & F17 & F18 & F19 & F20 \\
\hline Bina özellikleri & 15,8 & 15,8 & 42,2 & 15,8 & 42,2 & 12,2 & 42,2 & 42,2 & 42,2 & 15,8 \\
\hline Yangın güvenlik sistemleri & 46,8 & 46,8 & 47,3 & 43,8 & 16,3 & 45,4 & 47,6 & 47,6 & 47,4 & 41,8 \\
\hline Yönetim sistemleri & 8,4 & 8,4 & 2,5 & 8,4 & 2,5 & 8,4 & 10 & 3,9 & 8,4 & 8,4 \\
\hline Toplam Skor & 71 & 71 & 92 & 68 & 61 & 66 & 100 & 94 & 98 & 66 \\
\hline Yangın Güvenlik Risk Faktörleri & $\mathrm{F} 21$ & $\mathrm{~F} 22$ & $\mathrm{~F} 23$ & F24 & $\mathrm{F} 25$ & F26 & $\mathrm{F} 27$ & $\mathrm{~F} 28$ & F29 & F30 \\
\hline Bina özellikleri & 5 & 15,8 & 42,2 & 15,8 & 15,8 & 42,2 & 15,8 & 42,2 & 42,2 & 15,8 \\
\hline Yangın güvenlik sistemleri & 44,6 & 29,8 & 45,4 & 23,8 & 39,8 & 33,4 & 41,8 & 47,4 & 34,8 & 34,8 \\
\hline Yönetim sistemleri & 8,4 & 8,4 & 8,4 & 8,4 & 8,4 & 8,4 & 8,4 & 8,4 & 10 & 8,4 \\
\hline Toplam Skor & 58 & 54 & 96 & 48 & 64 & 84 & 66 & 98 & 87 & 59 \\
\hline
\end{tabular}

Sonuçlara göre, uygulama yapılan imalat tesislerinin sadece \% 7'sinde yangın güvenlik önlemleri mevzuat ve standartlara uygun durumda olmasına karşın, yaklaşık \% 67'si kısmen ya da büyük çoğunlukla yangın güvenliği açısından yetersiz durumdadır ve ciddi bir yangın riski altında çalışmalarını sürdürmektedir.

\section{SONUÇLAR}

Birçok eski ya da yeni binanın yangın güvenlik seviyesi, yürürlükteki mevzuat ve standartlara uygun durumda değildir. Bu durumun sebeplerinin başında yetersiz bakım ve kontrol gelmektedir. Birçok işyerinde günlük, haftalık, aylık ve yıllık bakım ve kontrolleri yapılmayan, çalışmayan, arızalı veya kusurlu tesisatlar bir sonraki denetime kadar devre dışı kalmaktadır. Bu şartlarda çalışan işletmeler ciddi yangın riski taşımaktadır. Ayrıca, eski binaların büyük çoğunluğu mevzuat ve standartlara uygun hale getirilebilecek durumda olmadığı gibi, uygun hale getirilmesi uzun zaman ve büyük masraf gerektirmektedir. İşletmeler bu masraf ve zaman kaybından kaçındığı için tesisatlar güvenli hale getirilememektedir.

İmalat işletmelerinde diğer işyerlerine göre yangın riskini arttıran tehlikeli üretim süreçleri söz konusudur. Bu işletmelerde yangın riskleri bina tasarımlarından, kullanılan hammadde ve ekipmanlardan kaynaklanabileceği gibi kusurlu veya kontrolü yapılmayan yangin tesisatlarından da kaynaklanmaktadır. Yangın tesisatı periyodik kontrollerin$\mathrm{de}$, kontrol listesi şeklinde yapılan risk analizleri nicel veriler içermediğinden yetersiz kalmaktadır. Mevcut geleneksel standart ve yöntemler, çoğunlukla alt yapısı kötü durumda olan eski binalardan oluşan tesislerin yangın güvenlik per- 
formansı konusunda sınırlı ve yetersiz değerlendirmelere neden olmaktadır. Bu nedenle, sıralama sistemi gibi nicel değerlendirmelere olanak veren bütüncül bir yaklaşım yangın risk analizlerinde tercih edilebilir. Sıralama sistemlerinin diğer bir avantajı da maliyet etkinliği ve kullanımının kolay olmasidır.

Sıralama yöntemi yüksek katlı ofis binaları ve öğrenci yurtları gibi bazı tesislerde de uygulanmış ve önerilmiştir. Sıralama sistemlerinin, çeşitli güvenlik gereklilikleri ve niteliklerinden dolayı, ofis binaları, öğrenci yurtları veya bu makalede vurgulanan imalat tesisleri gibi binaların kullanım tiplerine özgün olarak oluşturulduklarını belirtmek gerekir. Bununla birlikte, kullanım amacına göre farklı bina tiplerindeki yangın güvenlik seviyelerinin, farklı yöntemlerle desteklenerek daha ayrıntılı şekilde incelenmesi gerektiği de önerilmektedir.

\section{KAYNAKLAR}

[1] İBB. (2018), 2013-2018 Istatistikler. Eri im Tarihi: 07.04.2018, http://itfaiye.ibb.gov.tr

[2] İş Sağlığı Ve Güvenliği Kanunu (2012), T. C. Resmi Gazete, 28339, 30 Haziran 2012.

[3] Oturakçı, M., Dağsuyu C., (2017). Risk Değerlendirmesinde Bulanık Fine-Kinney Yöntemi ve Uygulaması, Karaelmas İs Să̆lğ̆ı ve Güvenliği Dergisi, 1, 17 25

[4] İş Ekipmanlarının Kullanımında Sağlık ve Güvenlik Şartları Yönetmeliği (2013), T. C. Resmi Gazete, 28628, 25 Nisan 2013.

[5] Binaların Yangından Korunması Hakkında Yönetmelik (2007), T. C. Resmi Gazete, 26735, 19 Aralık 2007.

[6] Kılıç, A., (2013). Yangın Riski. Yangın Ve Güvenlik Dergisi, 158, 8-10

[7] Manchester, S., Bardos, P., (2004). Fire Hazards from Self-Heating at Compositing and Waste Processing Sites. Environmental Technology Limited, Building Research Establishment Limited, Watford, UK, p. 9.
[8] Prete, L.D., Cefarelli, G., Nigro, E., (2016) "Calibration of a simplified method for fire resistance assessment of partially encased composite beams", Journal of Structural Fire Engineering, Vol. 7 Issue: 3, pp.262-282

[9] Özkan, E., Demirel, F., (2002). Çelik yapı bileşenlerinde alınması gereken yangın güvenlik önlemleri ve bir uygulama örneği (Yüksek Lisans Tezi). https:// www.tk.org.tr veri tabanından erişildi (07.04.2018)

[10] Tilehnoel, M.H., Aref, M.A., (2013). Temporal dimension evaluation by fuzzy TOPSIS method. International Journal of Architecture and Urban Development, 3(2), 55-60

[11] Özdemir, A.I., Seçme, N., (2009). İki aşamalı stratejik tedarikçi seçiminin bulanık TOPSIS yöntemi ile analizi. Afyon Kocatepe Üniversitesi 4.4.B.F. Dergisi, 10(2), 79-112

[12] Başkaya, Z., Öztürk, B. A. (2012). Tedarikçi değerlendirme probleminde bulanık TOPSIS algoritması ile grup karar verme ve karar vericilerin bireysel kararları arasındaki ilişkiler. Uluda) Üniversitesi 4.4. B.F. Dergisi, 21(1), 153-178

[13] Santos, F.J.J., Camargo, H.A. (2010) Fuzzy systems for multicriteria decisionmaking. Clei Electronic Journal, 13(3), 1-8

[14] Guozhong, Z., Neng, Z., Zhe, T., Ying, C., Bingul, S., (2012). Application of a trapezoidal fuzzy AHP method for work safety evaluation and early warning rating of hot and humid environments. Safety Science, 50(2), 228-239

[15] Janackovic, G.L., Savic, S.M., Stankovic, M.S., (2013). Selection and ranking of occupational safety indicators based on Fuzzy-Ahp: a case study in road construction companies. South African Journal of Industrial Engineering, 24(3), 175-189

[16] Dağdeviren, M., Yüksel, I., (2008). Developing a fuzzy analytic hierarchy process (AHP) model for behavior-based safety management. Information Sciences: an International Journal, 178 (6), 1717-1733

[17] Tadic, D., Djapan, M., (2012). A fuzzy model for assessing risk of occupational safety in the processing industry International Journal of Occupational Safety and Ergonomics, 18(2), 115-126

[18] Kim, D.I., Yoo, W.S., Cho, H., Kang, K.I., (2014). A fuzzy AHP-based decision support model for quantifying failure risk of excavation work. KSCE Journal of Civil Engineering, 18(7), 1966-1976

[19] Huang, Y.F., Hsu, K. H., Chein, P.S., Dong, S.H., (2011). Discussing performance index of human 
resource valuation with AHP-occupational safety section in T company in Taiwan as the case study. Information Technology Journal, 10(3), 549-556

[20] Janackovic, G. L., (2013). Delphi-Fuzzy AHP ranking of the occupational safety community of practice performance indicators. Journal of Management and Marketing, 1(1), 9-16

[21] Novin, V., Givehchi, S., Hoveidi, H., (2014). A novel fuzzy-based modeling for route safety management of hazardous materials. International Journal of Scientific \& Engineering Research, 5(8), 277-282

[22] Yarahmadi, R., (2012). Evaluating and prioritizing of performance indicators of health, safety, and environment using fuzzy TOPSIS. African Journal of Business Management, 6(5), 20-26

[23] Yilmaz, F., Alp, S., (2016). Underlying factors of occupational accidents: the case of Turkey. Open Journal of Safety Science and Technology, 6, 1-10

[24] Saaty, T.L., (1980). Multi Criteria Decision Making: The Analytical Hierarchy Process. McGraw-Hill, New York.

[25] Ünal, Ö.F., (2011). Analitik hiyerarşi prosesi ve personel seçimi alanında uygulamaları. Akdeniz Üniversitesi Uluslararasi Alanya İsletme Fakültesi Dergisi, 3 (2), 18-38

[26] Saaty, L.T., (1990). How to make a decision: the analytic hierarchy process. European Journal of Operational Research, 48, 9-26

[27] Gülsün, B., Yılmaz, F., (2016) Çalışma ortamına uygun zemin yapısının çok kriterli karar verme yöntemi (AHP) ile seçimi. Uluslararası Hakemli İş Güvenliği ve Çalışan Sağlığı Dergisi, s. 41-43

[28] Zhao, C.M., Lo, S.M., Lu, J.A., Fang, Z., 2004. A simulation approach for ranking of fire safety attributes of existing buildings. Fire Saf. J. 39 (7), 557-579.

[29] Watts, J.M., (1995). Fire risk ranking. İçinde: SFPE Handbook of Fire Prevention Engineering. National Fire Protection Association, Quincy, Mass., USA, s. 526.

[30] Hassanain, M. A., Hafeez, M. A., Sanni-Anibire, M. O., (2017) Ranking system for fire safety performance of student housing facilities. Safety Science, 92, 116-127

[31] Lo, S.M., (1999). A fire safety assessment system for existing buildings. Fire Technol. 35 (2), 131-152.

[32] Wong, L.T., Lau, S.W., 2007. A fire safety evaluation system for prioritizing fire improvements in old high-rise buildings in Hong Kong. Fire Technol. 43
(3), 233-249.

[33] Watts, J.M., 1997b. Fire risk assessment using multiattribute evaluation. In: Hasemi, Y. (Ed.), Proceedings of the 5th International Symposium on Fire Safety Science. Elsevier, London, pp. 679-690.

[34] Lo, S.M., (1998). A building safety inspection system for fire safety issues in existing buildings. Struct. Surv. 16 (4), 209-217.

[35] Chow, W.K., (2002). Proposed fire safety ranking system EB-FSRS for existing high-rise nonresidential buildings in Hong Kong. J. Archit. Eng. 8 (4), 116124.

[36] NFPA - 10lA, (1995). Guide on Alternative Approaches to Life Safety. National Fire Protection Association, Quincy.

[37] Watts, J.M., (1997a). Analysis of the NFPA fire safety evaluation system for business occupancies. Fire Technol. 33 (3), 276-282.

[38] Chow, W.K., Lui, G.C.H., 2002. Fire safety facilities assessment for karaokes. Facilities 20 (13/14), 441449.

[39] Watts Jr., J.M., Kaplan, M.E., (2001). Fire risk index for historic buildings. Fire technology 37 (2), 167180.

[40] Copping, A.G., 2002. Application of a systematic fire safety evaluation procedure in the protection of historic property. Fire Prot. Eng. 14, 19-25. 